
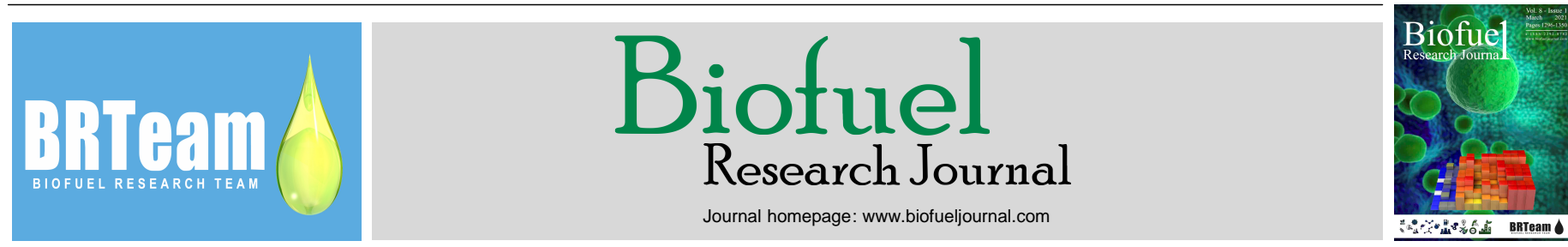

Original Research Paper

\title{
Optimization of microwave-assisted hydrothermal pretreatment and its effect on pyrolytic oil quality obtained by an auger reactor
}

\author{
Brenda J. Álvarez-Chávez ${ }^{1,2, *}$, Stéphane Godbout ${ }^{2}$, Vijaya Raghavan ${ }^{1}$ \\ ${ }^{I}$ Mc Gill University, Faculty of Agricultural and Environmental Sciences, Sainte-Anne-de-Bellevue, Canada. \\ ${ }^{2}$ Research and Development Institute for the Agri-Environment (IRDA), Québec, Canada.
}

\section{HIGHLIGHTS}

$>$ Microwave-assisted hydrothermal treatment (MHT) of biomass led to a decrease of $58 \%$ in ash content and $43 \%$ in extractives.

$>$ Pretreatment increased cellulose availability by $18.5 \%$ via hemicellulose reduction. $>$ MHT-pretreated hydrochar exhibited enhanced thermal stability during pyrolysis.

$>$ Pyrolyzed hydrochar increased bio-oil yield by $24 \%$ and decreased moisture by $35 \%$. $>$ Relative content of levoglucosan significantly increased by $127 \%$ in hydrochar bio-oil.

\section{GRAPHICAL ABSTRACT}

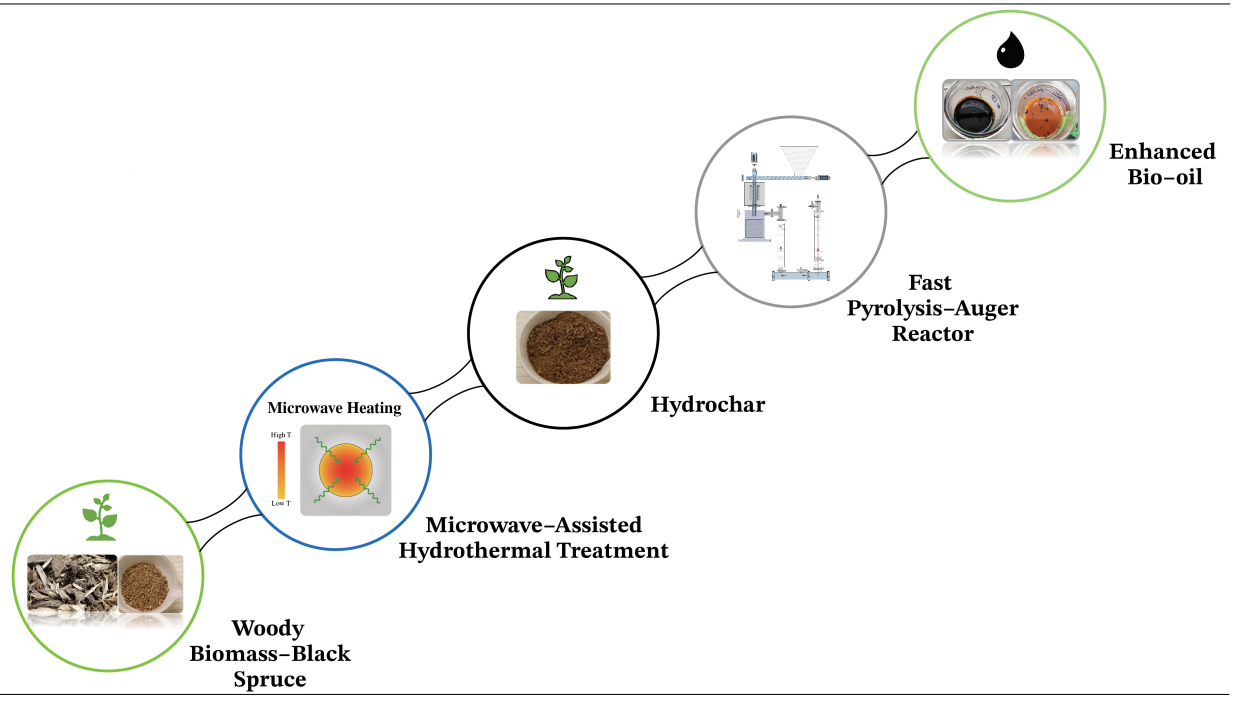

\section{ARTICLE INFO}

\section{Article history:}

Received 1 November 2020

Received in revised form 24 December 2020

Accepted 15 January 2021

Available online 1 March 2021

\section{Keywords:}

Microwave

Hydrothermal pretreatment

Fast pyrolysis

Bio-oil composition

Response surface methodology

\begin{abstract}
Microwave-assisted hydrothermal (MHT) treatment of biomass has received significant attention owing to energy efficiency during internal energy transfer and the additional benefits to the hydrochar produced in terms of physicochemical composition. Therefore, this study proposes the combination of MHT pretreatment with the fast pyrolysis process, to evaluate and optimize the effect of this treatment on the quality of the hydrochar and, consequently, on the quality of the bio-oil. The optimization of MHT treatment using black spruce was carried out, followed by fast pyrolysis of the hydrochar produced under optimal conditions in an auger reactor at $550{ }^{\circ} \mathrm{C}$ to obtain a high-quality bio-oil. As a result, the pretreated biomass showed on the one hand a significant decrease in the ash content by $58 \%$ and $43 \%$ in the content of the extractives. While on the other hand, the obtained hydrochar showed an increase in the availability of cellulose by $18.5 \%$ as a consequence of the reduction in the content of hemicellulose. Accordingly, hydrochar showed an increase in thermal stability during pyrolysis and it produced a higher total bio-oil yield, increasing by $24 \%$. Most importantly, the oil obtained showed a $35 \%$ reduction in moisture content. Chemical composition of the oil was qualitatively examined through GC-MS analysis. It was observed that the bio-oil showed a dramatic increase in the relative content of levoglucosan, by $127 \%$. A bio-oil with the characteristics obtained would be a suitable candidate for use in boilers for heating purposes or chemical extraction.
\end{abstract}

(c) 2021 BRTeam. All rights reserved.

* Corresponding author at: Tel.: +1 5143988731

E-mail address: brenda.alvarezchavez@mail.mcgill.ca

Please cite this article as: Álvarez-Chávez B.J., Godbout S., Raghavan V. Optimization of microwave-assisted hydrothermal pretreatment and its effect on pyrolytic oil quality obtained by an auger reactor. Biofuel Research Journal 29 (2021) 1316-1329. DOI: 10.18331/BRJ2021.8.1.3 


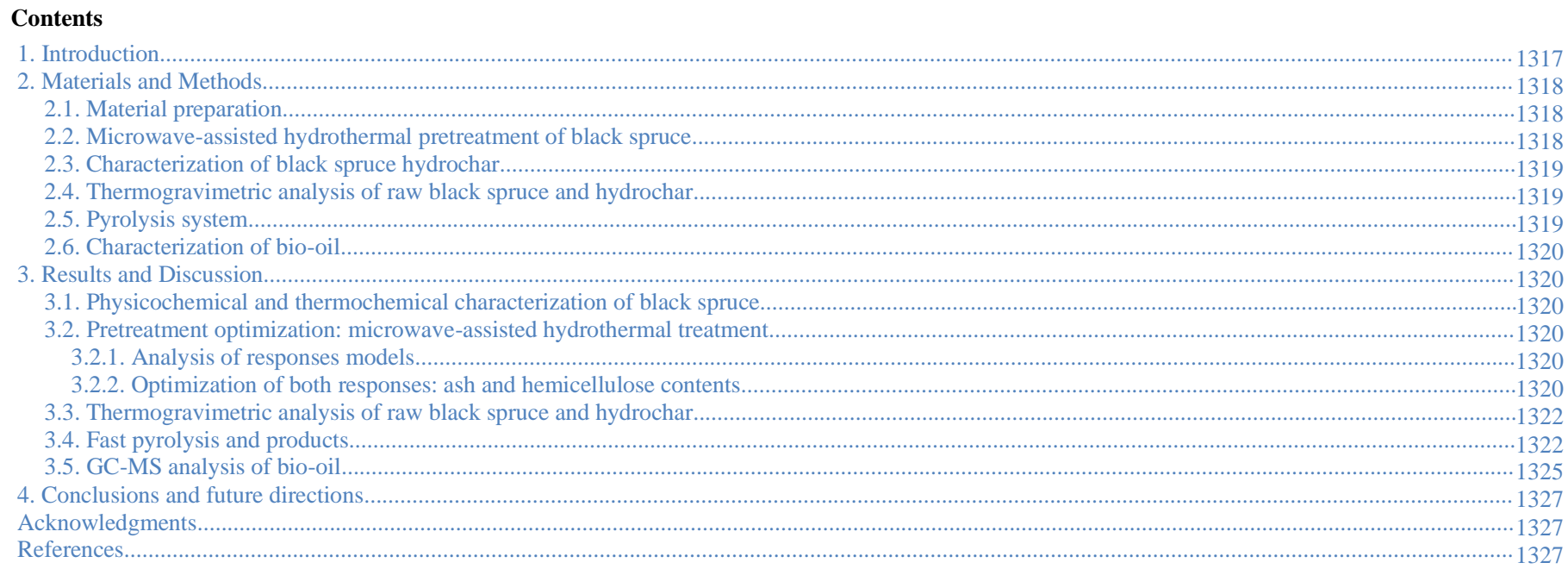

\section{Introduction}

The development of green technologies has emerged in recent years as a solution to the environmental crises caused by the growing utilization of fossil fuels. Fast pyrolysis is a promising green technology that uses biomass for the production of bio-oil, gas, and biochar. The pyrolytic oil produced is regarded as a potential substitute for fossil fuels in stationary combustion applications (Kalargaris et al., 2017; Krutof and Hawboldt, 2020) or can be used in diesel blends (Krutof and Hawboldt, 2016). Nevertheless, bio-oil quality remains poor and is limited by its chemical stability associated with aging, the low calorific value related to the high water content, the formation of deposits due to high solids and ash content, and high acidity and viscosity (Krutof and Hawboldt, 2016; Imran et al., 2018; Pourkarimi et al., 2019; Qureshi et al., 2019). Hence, some upgrading techniques can be applied to biomass prior to pyrolysis for biooil to be used in stationary combustion applications such as thermal, chemical or biological pretreatments (Dai et al., 2018; Soltanian et al., 2020).

The use of pretreatments on biomass favors the production and quality of bio-oil and it has been studied as a viable method for the establishment of a production chain in the future. Chemical components of biomass and their interactions during pyrolysis play an important role in the quality and yield of products (Hilbers et al., 2015; Yu et al., 2017). Thermal pretreatments are generally used for the structural destruction of lignin and hemicellulose, hence increasing the availability of cellulose content. Hydrothermal treatment, among all thermal pretreatments, is characterized by solubilizing hemicellulose into aqueous compounds using saturated water as medium at a temperature of 150 $260{ }^{\circ} \mathrm{C}$ (Chang et al., 2013), preserving cellulose for the pyrolysis process (Holopainen-Mantila et al., 2013; Zheng et al., 2015). In addition, lower energy consumption has been reported in comparison with the other thermal treatments such as torrefaction, due to its lower temperature, resulting in reduced ash content and biochar yield (Kambo and Dutta, 2015; Alvarez-Chavez et al., 2019b). After applying a hydrothermal pretreatment to the biomass, some of the changes in its physicochemical composition that have been reported are an improvement in the grindability and hydrophobicity (Le Roux et al., 2015; Dai et al., 2017), a decrease in the proportion of alkalis contained in the biomass (Zheng et al., 2015; Yao and Ma, 2018), and an increase in the fixed carbon and calorific value with no effect on the volatile content (Wu et al., 2015).

The use of hydrothermally-pretreated biomass in fast pyrolysis results in a bio-oil with a lower content of acids, furans, ketones and aldehydes (Chang et al., 2013; Zheng et al., 2015; Yao and Ma, 2018). On the other hand, it significantly increases the production of sugars and phenolic compounds during pyrolysis (Le Roux et al., 2015; Dai et al., 2017 and 2018; Yao and Ma, 2018).

The use of microwave technology has triggered great interest to perform hydrothermal treatment due to its advantages over the use of conventional technologies, a lower cost, a shorter time taken to obtain optimal results, and a higher energy efficiency during treatment (Beneroso et al., 2017). The difference between the conventional and microwave heater resides in the type of heat transfer. The first one occurs by conduction or convection from the outside to the inside, i.e., from the heater to the surface of the reactor vessel and then to the sample, water, and substrate. Consequently, the surface of the sample remains at a higher temperature than the core. In contrast, the hydrothermal treatment by microwave radiation occurs from the inside to the outside, by direct coupling of electromagnetic waves (in the range of $300 \mathrm{MHz}$ and $300 \mathrm{GHz}$ ) with the dipoles present in the reaction mixture. Correspondingly, the core of the sample generally remains at a higher temperature than the surface during the heating process (Bhattacharya and Basak, 2016; Sharma et al., 2020). In Figure 1, this difference in the heating mechanism between the two technologies can be clearly seen. The conversion of electromagnetic energy into thermal energy that occurs in microwave heating produces much faster heating rates than those observed in conventional heating, reducing reaction times to a few minutes (Sharma et al., 2020). Furthermore, microwave heating offers an improved heat distribution and it can break down hydrocarbon components present in the biomass into lighter components (Lam et al., 2019b). Microwave technology has been generally explored in recent years for its advantages over conventional technology in processing biomass to improve its quality before pyrolysis, or in performing the pyrolysis reaction (Lam et al., 2019a and b).

Dai et al. (2017) compared microwave and conventional hydrothermal pretreatment of bamboo sawdust. As a result, they reported that based on the ultimate and proximate analysis, microwave technology provided better results than the conventional, increasing higher heating value (HHV) and decreasing oxygen content. This was due to the increased removal of acetyl groups present in the hemicellulose. In a subsequent study, Dai et al. (2018) evaluated the effect of temperature and time during microwave-assisted hydrothermal pretreatment on hydrochar properties and behavior during pyrolysis. As a result, an increase in both calorific value as well as fixed carbon content and a reduction in oxygen content in hydrochar were reported at higher treatment severity, in accordance with the previous study. Furthermore, a significant increase in sugar content was observed due to the greater availability of cellulose.

Although studies on microwave-assisted hydrothermal pretreatment are very scarce, this technology appears to be promising in the long term for obtaining a higher quality of bio-oil. However, there is a need to standardize and further analyze through statistical techniques, such as surface response, the effect of such hydrothermal pretreatments on key biomass properties and their final effect on pyrolytic oil quality. This study offers both processes, the microwave-assisted hydrothermal pretreatment optimization using black spruce and its subsequent evaluation in a fast pyrolysis auger reactor. This type of pyrolytic reactor has been recognized as one of the best for its versatility in the transformation of various types of biomass through fast, slow, and intermediate pyrolysis. Furthermore, it can be used 


\section{Conventional Heating}

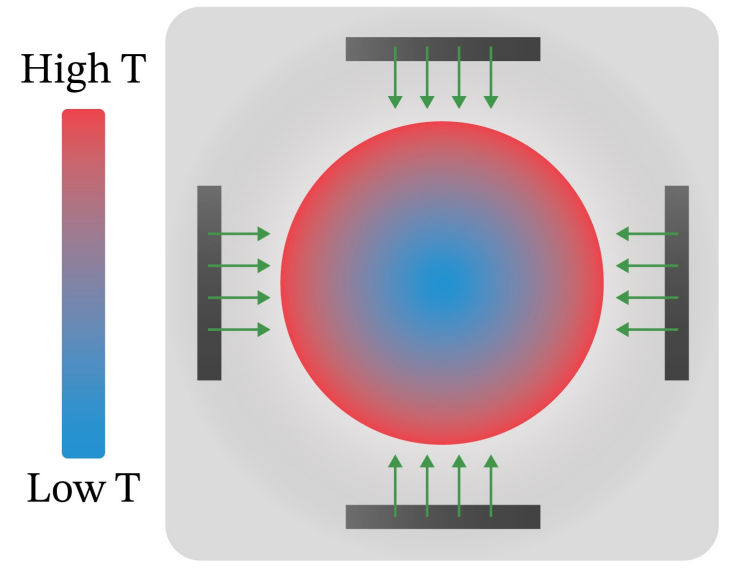

\section{Microwave Heating}

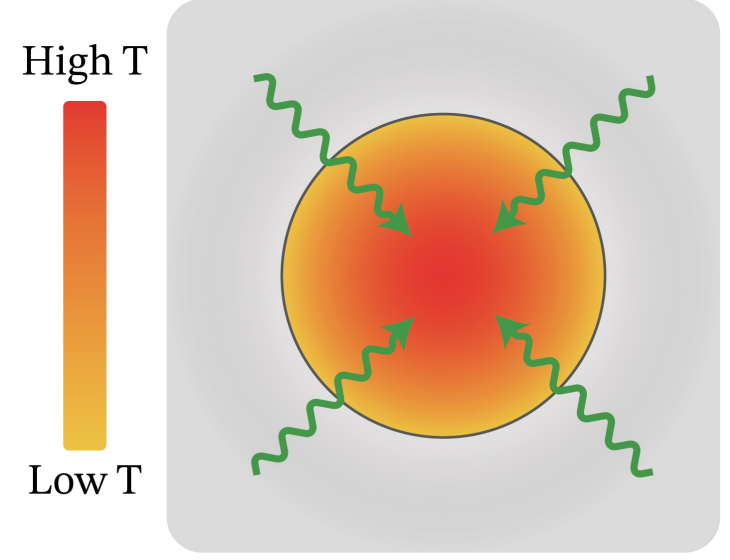

Fig. 1. Conventional and microwave-induced heating patterns. Adapted from Bhattacharya and Basak (2016).

as a portable installation for places with infrastructure and accessibility restrictions, as well as having a simple design that favors heat transfer during pyrolysis (Campuzano et al., 2019; Jalalifar et al., 2020).

For more details of present study, optimization of microwave-assisted hydrothermal pretreatment is carried out using the Central Rotating Composite Design (CCRD) with three variables: temperature, time, and biomass-water ratio during pretreatment. Two responses are analyzed through response surface methodology to evaluate the effect of the variables, hemicellulose and ash content in the produced hydrochar. Subsequently, the optimum hydrochar with the lowest ash and hemicellulose content is pyrolyzed in an auger reactor. And finally, the quality of the products is evaluated, and solid recommendations are made. The aim of this study is to evaluate the effect of microwave-assisted hydrothermal pretreatment using pyrolytic oil quality through statistical analysis to standardize and optimize such processes, using black spruce as raw material.

\section{Materials and Methods}

\subsection{Material preparation}

Black spruce (Picea mariana Mill.) used for this study was provided by the Research and Development Institute in Agri-Environment (IRDA) (Deschambault, QC, Canada). The selected biomass was obtained in two different batches six months apart, which corresponds to a mixture of wood, bark and impurities, giving its nature as forest waste. Prior to performing the experimental work, the biomass sample was ground to small particle size of $1.0-2.4 \mathrm{~mm}$. Then it was dried at $105{ }^{\circ} \mathrm{C}$ for $12 \mathrm{~h}$ to around $3 \mathrm{wt} \%$ moisture content. The two biomass batches were physically and chemically characterized. Cellulose, hemicellulose, and lignin were analyzed according to the AFNOR XP U44-162 method. Heating value was determined using an adiabatic bomb calorimeter (Parr Oxygen Bomb Model 1341EB, Calorimeter Thermometer Model 6772, Parr Instrument Company, Moline, IL, USA). Ash content was obtained using the standard EN 14775 for solid biofuels, at $550^{\circ} \mathrm{C}$.

The first batch of biomass was applied for the evaluation and optimization of the microwave-assisted hydrothermal pretreatment and the second batch was applied for the evaluation of fast pyrolysis.

\subsection{Microwave-assisted hydrothermal pretreatment of black spruce}

The hydrothermal pretreatment of black spruce was carried out using a Mini WAVE Digestion Module (SCP Science Canada) that operates at a frequency of $2.45 \mathrm{GHz}$ using 6 cylindrical quartz reactor vessels of $50 \mathrm{~mL}$. The equipment is available at the post-harvest lab of Bioresource Engineering Department of McGill University (Canada).

Response surface analysis was used to define the effect of temperature, time, and biomass-water ratio during pretreatment on the chemical composition of biomass as well as the effect on calorific value. The response surface analysis was performed using Design Expert software (version 7.0 Stat-Ease Inc. Minneapolis, MN, USA). The experimental design was based on the Central Composite Rotatable Design (CCRD) with 19 experimental runs. This design combines $n_{F}$ factorial runs, $2^{k}$ axial runs, and $\mathrm{C}_{0}$ center points. The rotatable aspect of the design is given by the choice of the axial runs $(\alpha)$, which represent the extreme values (low and high). For three variables (temperature, time, and biomass- water ratio), the value of $\alpha$ is 1.682 (Ferreira et al., 2007). The number of factorial runs for the three variables were 8 factorial runs, 6 axial points, and 5 central points. Table 1 shows the factors and the levels proposed in the experimental design.

Table 1.

Experimental factors and levels used in Central Composite Rotatable Design.

\begin{tabular}{lcccccc}
\hline \multirow{2}{*}{ Factors } & Variable & \multicolumn{5}{c}{ Levels } \\
\cline { 3 - 7 } & & $\mathbf{- \alpha}$ & $\mathbf{- 1}$ & $\mathbf{0}$ & $\mathbf{+ 1}$ & $+\boldsymbol{\alpha}$ \\
\hline Temperature $\left({ }^{\circ} \mathrm{C}\right)$ & $\mathrm{A}$ & 110 & 120 & 135 & 150 & 160 \\
Time $(\min )$ & $\mathrm{B}$ & 6.4 & 20 & 40 & 60 & 73.6 \\
Biomass-water ratio & $\mathrm{C}$ & $1: 8$ & $1: 10$ & $1: 13$ & $1: 16$ & $1: 18$ \\
\hline
\end{tabular}

The microwave-assisted hydrothermal (MHT) experiments were conducted in duplicate using $3 \mathrm{~g}$ of biomass from the batch, $1 \mathrm{~g}$ in each vessel. The pressure in the reaction vessel was that associated with the temperature used for each experiment. For all the experiments, the mixture of black spruce and distilled water was introduced and homogenized in the $50 \mathrm{~mL}$ reaction vessel and then sealed. After achieving the MHT pretreatment, the reaction vessels were cooled to room temperature and then black spruce was filtered, washed three times with distilled water, and finally dried at $105{ }^{\circ} \mathrm{C}$ for $12 \mathrm{~h}$. The black spruce resulting from the MHT treatment is referred to in this study as hydrochar.

By conducting response surface analysis, pretreatment optimization was proposed to locate the optimal values to decrease both responses, i.e., the 
optimal values to decrease hemicellulose and ashes in the biomass. The operational conditions calculated by the response surface analysis software were carried out to apply the MHT pretreatment to the biomass, for the subsequent fast pyrolysis stage.

\subsection{Characterization of black spruce hydrochar}

The black spruce hydrochar, produced with the MHT pretreatment, was characterized following the same methods of analysis of the raw material. Cellulose, hemicellulose, and lignin were analyzed according to the AFNOR XP U44-162 method. Heating value was determined using an adiabatic bomb calorimeter (Parr Oxygen Bomb Model 1341EB, Calorimeter Thermometer Model 6772, Parr Instrument Company, Moline, IL, USA). Ash content was obtained using the standard EN 14775 for solid biofuels, at $550{ }^{\circ} \mathrm{C}$.

\subsection{Thermogravimetric analysis of raw black spruce and hydrochar}

In order to analyze and understand the thermal behavior of raw biomass and hydrochar, a thermogravimetric (TG) analysis was performed. The equipment used was a TGA Q50 (TA Instruments, DE, USA). Prior to TG analysis, the samples were sieved into a mesh No. 60 and then dried at $105{ }^{\circ} \mathrm{C}$ until a constant weight was reached. High purity nitrogen was used to provide the inert atmosphere needed to perform pyrolysis. The TG analyses were performed following the method of stabilization at $25^{\circ} \mathrm{C}$ and heating up to $800{ }^{\circ} \mathrm{C}$ at a rate of $10^{\circ} \mathrm{C} \mathrm{min}^{-1}$ under a stream of $60 \mathrm{~mL} \mathrm{~min}^{-1}$ of $\mathrm{N}_{2}$.

\subsection{Pyrolysis system}

The pyrolysis tests were performed using the black spruce hydrochar resulting from the optimization of the MHT pretreatment (optimal hydrochar) and the untreated black spruce from batch 2 , in order to evaluate the effect of the pretreatment on pyrolytic oil quality.

Fast pyrolysis experiments were carried out in a lab-scale auger reactor with a capacity of 0.1-4.0 $\mathrm{kg} \mathrm{h}^{-1}$ (Patent CA 2830968), located at the IRDA research centre (Deschambault, QC, Canada). The schematic diagram of the pyrolysis system is shown in Figure 2. This system is also described in previous research studies (Brassard et al., 2018; Alvarez-Chavez et al. 2019a). The system mainly consists of one feeding hopper, two screw

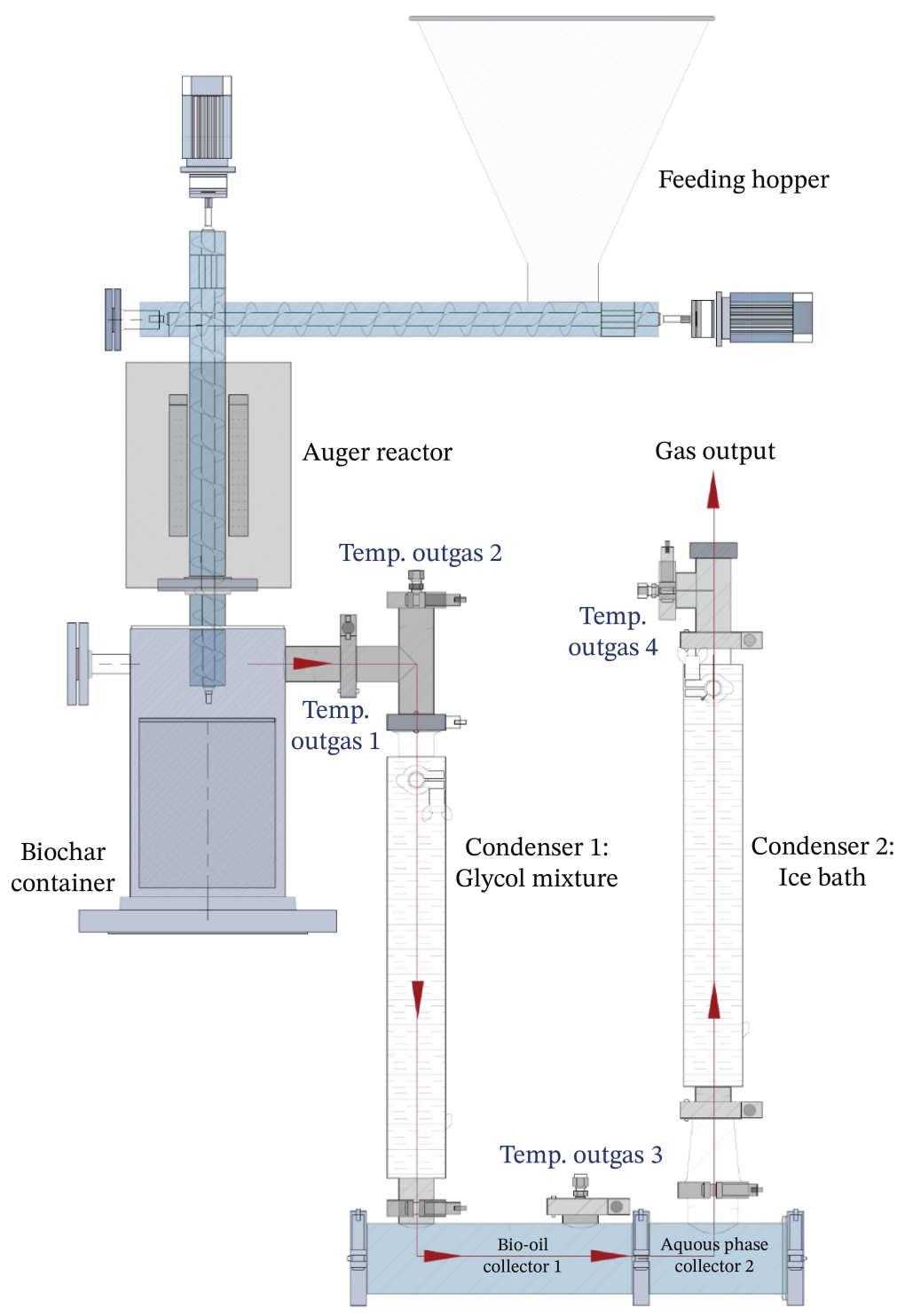

Fig. 2. Experimental set-up for black spruce pyrolysis. 
conveyors, an auger reactor with two $1500 \mathrm{~W}$ heating elements, a biochar container, two condensers, and two bio-oil containers. Thermocouples were installed at different positions in the system and data was collected every $10 \mathrm{~s}$ using a data logger (CR10X, Campbell Scientific, Edmonton, AB, Canada). Nitrogen was used as carrier gas.

The operational conditions of the fast pyrolysis were taken from a previous study (Alvarez-Chavez et al., 2019a), where this auger reactor was optimized for obtaining bio-oil with less water content and higher yield. The conditions used were: $555^{\circ} \mathrm{C}$ for the reaction temperature, $129 \mathrm{~s}$ for the residence time of the solids $\left(0.47 \mathrm{~kg} \mathrm{~h}^{-1}\right)$, a nitrogen flow of $6.91 \mathrm{~min}^{-1}$, temperature of the first condenser of $120^{\circ} \mathrm{C}$ using a glycol-water mixture, and the temperature of the second condenser of $4-5^{\circ} \mathrm{C}$ using an ice bath. The bio-oil was recovered in two different collectors, the liquid product recovered in the first collector connected to the first condenser is referred to as "bio-oil" and the liquid product recovered in the second collector connected to the second condenser is referred to as " aqueous phase."

Four fast pyrolysis tests were performed using $600 \mathrm{~g}$ of biomass each. Two pyrolysis tests were performed with raw black spruce of batch 2 , and two tests with pretreated black spruce using the optimal conditions of the MHT pretreatment resulting from previous stage. The number of tests was decided considering the repeatability and accuracy of the pyrolysis system.

\subsection{Characterization of bio-oil}

The physical properties of the bio-oil were analyzed, such as water content. Water content was determined by Karl Fisher titration method. Average of three analyses were reported. The chemical components of the bio-oil were identified through a gas chromatography-mass spectrometer (GC-MS Agilent $6890 \mathrm{~N})$ equipped with an HP-5MS column. The analysis samples were prepared by dissolving around $250 \mathrm{mg}$ of bio-oil in $10 \mathrm{~mL}$ of GC grade acetone. Then, solutions were filtered through a $0.45 \mu \mathrm{m}$ PTFE filter. The sample size used in the GC analysis was $0.1 \mu$. The $\mathrm{GC}$ oven was programmed at $45^{\circ} \mathrm{C}$ for $3 \mathrm{~min}$ and it was increased at a rate of $5{ }^{\circ} \mathrm{C} \mathrm{min}^{-1}$ up to $260{ }^{\circ} \mathrm{C}$, and finally held at isothermal regime for $5 \mathrm{~min}$. The injector temperature was $260{ }^{\circ} \mathrm{C}$ and the split ratio was set to 50:1. The mass spectrometer was operated with an ionization energy of $70 \mathrm{eV}$. Helium was used as carrier gas at a flow of $1.0 \mathrm{~mL}$ $\mathrm{min}^{-1}$. The identification of the main chromatographic peaks was made using the NIST mass spectral library (National Institute of Standards and Technology) (Shen et al. 2017) and available literature.

\section{Results and Discussion}

\subsection{Physicochemical and thermochemical characterization of black spruce}

Since the black spruce biomass used was obtained in two different lots six months apart, the characterization of both was performed. Both batch biomass consists of a mixture of wood, bark, and impurities, giving its nature as forest waste. Table 2 presents the chemical composition of black spruce (named BS) from both batches, including cellulose, hemicellulose, lignin, and soluble extracts, as well the heating value and ash content. The chemical composition of biomass in general is similar. However, there is a significant difference in the ash content, since Batch 2 contained more impurities due to the biomass mixture.

\subsection{Pretreatment optimization: microwave-assisted hydrothermal treatment}

\subsubsection{Analysis of responses models}

The response surface methodology was used to evaluate the effect of the three variables (A: temperature of treatment, B: time of treatment, and C: biomass-water ratio), on the chemical composition (content of cellulose, hemicellulose, and lignin) of biomass as well as the effect on the calorific value. However, the results showed that significant models could only be obtained to predict and evaluate the effect of the three variables on ash content $\left(\mathrm{Y}_{1}\right)$ and hemicellulose content $\left(\mathrm{Y}_{2}\right)$. This coincides with the properties of biomass that have the greatest impact on the quality of the bio-oil obtained when this biomass is pyrolyzed. The three independent variables were correlated with the experimental responses in order to minimize both responses. The response model obtained using the Design Expert software for ash content $\left(\mathrm{Y}_{1}\right)$ was of
Table 2.

Physicochemical characteristics of the two batches of black spruce.

\begin{tabular}{lcc}
\hline Physicochemical characteristics a $^{\text {a }}$ & BS Batch 1 & BS Batch 2 \\
\hline Cellulose (wt\%) & 35.7 & 34.8 \\
Hemicellulose (wt\%) & 9.81 & 8.23 \\
Lignin (wt\%) & 31.1 & 34.8 \\
Soluble extracts (wt\%) & 23.4 & 22.1 \\
\hline
\end{tabular}

${ }^{\mathrm{a}}$ Dry basis

second order. The results were significant at a level of 0.05 . The only significant variable was the pretreatment temperature. For quadratic terms, only time was significant. Since there were some insignificant terms, the reduction of the complete quadratic model was carried out. However, the interaction between the significant factor, and the other two factors was maintained in the models to observe their effect with the response surface analysis. The reduced model was highly significant with a p-value of < 0.0133, and it is shown with coded factors in Equation 1.

Ash content $(\%)=1.23-0.24 A-0.05 B+9.96^{-5} C+$ $0.10 A B-0.10 A C+6.25^{-3} B C+0.18 C^{2}$

Eq. 1

Figure 3 shows the response surface for the ash content. The graphs correspond to the interaction between the most significant variable, treatment temperature, with the other two variables. In Figure 3a, the interaction between temperature and time used during the MHT treatment is shown. It was observed that the minimum value of ash content was obtained using the highest value for temperature $\left(160{ }^{\circ} \mathrm{C}\right)$ and at approximately $40 \mathrm{~min}$ of pretreatment duration. In Figure $3 \mathrm{~b}$, the interaction between temperature and the ratio of biomass-water is observed Although in the model, the ratio of biomass-water is not significant, it can be seen that it slightly affects ash content. The higher the ratio, the lower the ash content.

The response model obtained using the Design Expert software for the hemicellulose content $\left(\mathrm{Y}_{2}\right)$ was fitted in a linear model. The results were significant at 0.05 level. The linear terms of the temperature of the treatment (A) and the time of treatment (B) were both significant. The linear model was highly significant with a p-value of $<0.0025$. The reduced model with coded factors is shown in Equation 2.

Hemicellulose content $(\%)=8.61-0.76 A-0.55 B+0.24 C \quad$ Eq. 2

\subsubsection{Optimization of both responses: ash and hemicellulose contents}

The optimization of the MHT pretreatment was carried out to minimize ash content and hemicellulose present in the black spruce, through response surface methodology. The optimal values calculated for the independent variables using the Design Expert Software were: $160{ }^{\circ} \mathrm{C}$ for the temperature (A), 40 min for the time (B) and 1:13 for the ratio of biomasswater $(\mathrm{C})$. At optimal conditions, the expected response for the ash content $\left(\mathrm{Y}_{1}\right)$ is $0.83 \mathrm{wt} \%$ and the expected hemicellulose content $\left(\mathrm{Y}_{2}\right)$ is $7.34 \mathrm{wt} \%$, estimated using Equations 1 and 2. Table 3 shows a comparison of the chemical composition of raw black spruce and the hydrochar under optimal conditions. The values of both responses in the black spruce hydrochar are very close to those estimated with the model. Thus, the model confirmed the capability of prediction. It can be observed that the MHT treatment can reduce ash content by $58 \%$ and the hemicellulose content by only $12.5 \%$. Besides these two main responses, a decrease in soluble extracts by $43 \%$ 
$\mathbf{a}$

Design-Expert ${ }^{\circledR}$ Software

Ash content

Ash content

- Design Points

2.07

0.91

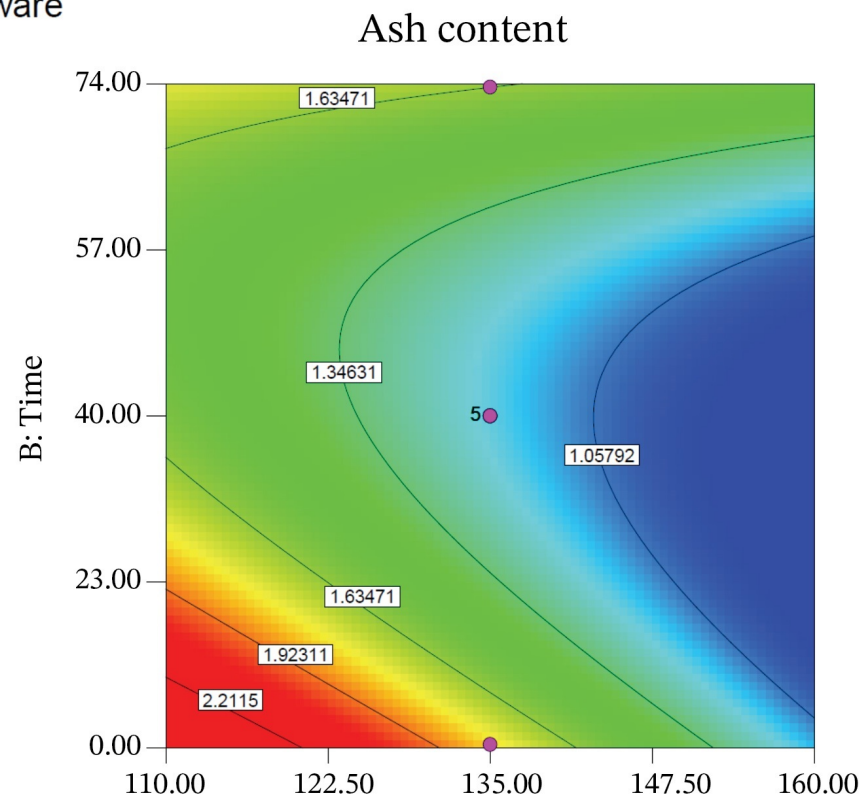

$\mathrm{X} 1=\mathrm{A}:$ Temperature

$\mathrm{X} 2=\mathrm{B}$ : Time

Actual Factor

C: Biomass-water ratio

\section{b}

\section{Design-Expert ${ }^{\circledR}$ Software}

\section{Ash content}

Ash content
Design Points
2.07
0.91

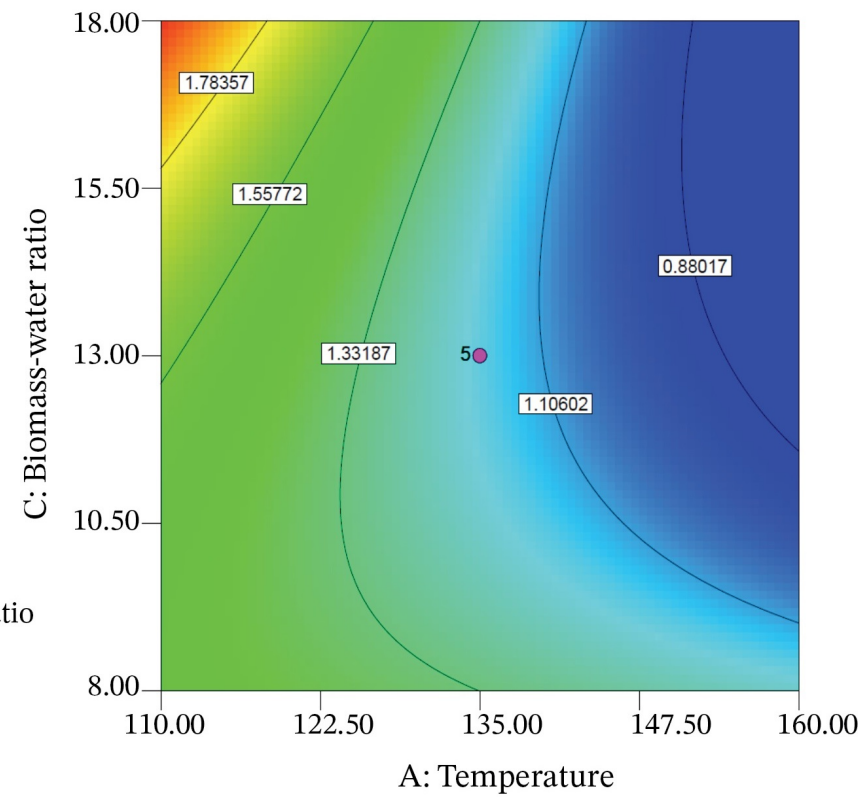

Fig. 3. Response surface plot of ash content. (a) Interaction $A B$, temperature and time. (b) Interaction AC, temperature and biomass-water ratio.

was observed. An increase in cellulose and lignin content after the MHT pretreatment by $18.5 \%$ and $15.43 \%$, respectively, was obtained in the hydrochar. Nevertheless, no change in the calorific value was found. On the other hand, a change in the coloring of the biomass was observed.
Consequently, a biomass with better characteristics for pyrolysis was obtained using the MHT pretreatment.

The MHT pretreatment significantly reduced the ash content at the maximum temperature tested. The decrease in ash content was due to the 
Table 3

Chemical composition of raw black spruce and black spruce hydrochar.

\begin{tabular}{lcc}
\hline Physicochemical characteristics a & Raw black spruce & Black spruce hydrochar \\
\hline Cellulose (wt\%) & 35.7 & 42.30 \\
Hemicellulose (wt\%) & 9.81 & 8.58 \\
Lignin (wt\%) & 31.1 & 35.90 \\
Soluble extracts (wt\%) & 23.4 & 13.30 \\
Heating value HHV (MJ kg-1) & 20.62 & 20.11 \\
Ash content (wt\%) & 1.88 & 0.79
\end{tabular}

${ }^{\text {a }}$ Dry basis

removal of minerals from the biomass during pretreatment, as the saturated water acts as a catalyst in the reaction facilitating the demineralization process (Alvarez-Chavez et al., 2019b). This trend of ash reduction with increasing temperature has also been observed in hydrothermal pretreatments using conventional furnaces. In a study by Wu et al. (2015) which was conducted to evaluate the effect of this treatment with conventional technology, a similar ash reduction was observed, $60 \%$ when using bamboo sawdust as biomass under conditions of $190{ }^{\circ} \mathrm{C}$ for $30 \mathrm{~min}$; at $200{ }^{\circ} \mathrm{C}$ for $20 \mathrm{~min}$ the ash content was reduced by $55 \%$; and, at $230{ }^{\circ} \mathrm{C}$ for $20 \mathrm{~min}$ the ash content was reduced by $61 \%$. In a similar study by Yao and Ma (2018), discrete results were presented for the palm tree with a decrease of about $20 \%$ in ash content using $210{ }^{\circ} \mathrm{C}$ for $60 \mathrm{~min}$. In contrast, the use of microwave technology in pretreatment results in the same tendency to reduce the ash content but at lower temperature and/or time. Research conducted by Dai et al. (2018) showed that MHT pretreatment at a power of $800 \mathrm{~W}$ to reach $210{ }^{\circ} \mathrm{C}$ in $35 \mathrm{~min}$ reduced around $92 \%$ of the ash content, and $230{ }^{\circ} \mathrm{C}$ in $15 \mathrm{~min}$ reduced around $92 \%$ of the ash content, moreover the treatment enhanced the carbon content and heating value.

\subsection{Thermogravimetric analysis of raw black spruce and hydrochar}

TG and derived thermogravimetric (DTG) curves are commonly used to understand and analyse the pyrolysis behaviour of biomass and hydrochars. Generally, thermal decomposition of biomass occurs in three stages. The first stage corresponds to the evaporation of water and the partial degradation of light organic compounds, which occurs in the range from room temperature to approximately $240{ }^{\circ} \mathrm{C}$. In the second stage, the main process of devolatilization of hemicellulose, cellulose, and lignin present in the biomass is observed, which ranges from approximately 200 to $400{ }^{\circ} \mathrm{C}$. And finally, in the third stage, which ranges between 400 and $800^{\circ} \mathrm{C}$, the carbonization process occurs (Zhang et al., 2016; Dai et al., 2018). Therefore, TG and DTG analyses were performed on the hydrochar samples from the 19 runs of the experimental design, as well as on the initial biomass and on the hydrochar at optimal conditions of the MHT pretreatment.

Figure 4 shows the TG and DTG curves of the axial points of the central composite design in which the effect of each independent variable on the pyrolytic behaviour of hydrochars can be clearly seen. The figure consists of three panels, where in each panel the hydrochar samples obtained at the extreme values of the experimental design are compared with the initial biomass. In Figure 4a, the TG curves corresponding to the axial points of the temperature $\left(110^{\circ} \mathrm{C}\right.$ and $\left.160{ }^{\circ} \mathrm{C}\right)$ together with the central points for the other two variables (40 min and biomass-water ratio of 1:13) are presented. The DTG curve of the raw biomass shows the small shoulder corresponding to the decomposition of hemicellulose, which occurs at about $300{ }^{\circ} \mathrm{C}$, as well as the larger curve corresponding to the decomposition of cellulose, which occurs at about $360^{\circ} \mathrm{C}$ (Ren et al., 2013; Dai et al., 2018). Since temperature is the most significant variable to decrease hemicellulose, it is proven that after using $160{ }^{\circ} \mathrm{C}$ in the MHT pretreatment, the hemicellulose curve practically disappears. The value of the TG derivative also turned out to be the highest in all the experiments performed, with a weight loss rate value of $20.1 \% \mathrm{~min}^{-1}$. Figure $4 \mathrm{~b}$ shows the effect of the residence time of MHT pretreatment on thermal decomposition of hydrochars. Although time is not as statistically significant as the temperature, it can be seen that it has the same effect as the use of high temperatures, even if the temperature is lower. When the pretreatment time was $73 \mathrm{~min}$ at a temperature of $135^{\circ} \mathrm{C}$, a significant value of the weight loss rate was obtained $\left(18.8 \% \mathrm{~min}^{-1}\right)$, as well as the elimination of the hemicellulose curve. Finally, Figure $4 \mathrm{c}$ demonstrates that there is no significant effect on the hemicellulose curve or weight loss rate value due to the biomass-water ratio during MHT pretreatment.

Table 4 compares the typical parameters of TG decomposition of hydrochar samples corresponding to the axial points of the experimental design, optimal hydrochar samples, and raw black spruce. The aim of Table 4 is to show the thermal behavior of samples during pyrolysis. These characteristic parameters of TG decomposition are initial decomposition temperature $\left(\mathrm{T}_{\mathrm{i}}\right)$, which corresponds to the weight loss of about $5 \mathrm{wt} \%$; temperature of maximum loss rate $\left(\mathrm{T}_{\max }\right)$ which corresponds to DTG max; final temperature $\left(\mathrm{T}_{\mathrm{f}}\right)$; and differential temperature of initial and final temperature. It can be found from Table 4 that MHT pretreatment increased the $T_{i}$ and $T_{\max }$ of all the samples. In accordance with Table 4, it is shown that the highest values for $T_{i}$ and $T_{\max }$ are obtained using the maximum pretreatment temperature $\left(160^{\circ} \mathrm{C}\right)$, followed by the values obtained for the maximum time used during pretreatment $(73.6 \mathrm{~min})$.

When comparing the thermal decomposition parameters of raw black spruce with those of hydrochar obtained under optimal conditions, a decrease in the temperature differential at which the decomposition of the materials occurs was found, from 132.9 to $118.2^{\circ} \mathrm{C}$. Moreover, an increase in the mass loss rate (DTG) from 14.2 to $17.0 \% \mathrm{~min}^{-1}$ was observed. These results indicate that through MHT treatment an improved cellulose content and greater thermal stability can be achieved in biomass, facilitating pyrolysis. Similar phenomenon was observed in other studies of hydrothermal pretreatment (Zheng et al., 2015; Dai et al., 2017). This enhanced thermal stability during pyrolysis also occurs in other types of pretreatment such as acid washing (Asadieraghi and Daud, 2014) or ionic liquids (Brunner et al., 2019).

\subsection{Fast pyrolysis and products}

The pyrolysis of raw black spruce and hydrochar was performed in duplicate, as the reproducibility of the test results has been previously demonstrated by the pyrolysis system (Alvarez-Chavez et al., 2019a). The pyrolysis conditions were the same for both materials, regarding pyrolysis temperature, nitrogen flow, and temperature in both condensers. Figure 5 shows the temperature profiles of raw black spruce and optimal hydrochar during pyrolysis, including the reaction temperature and the vapor temperatures produced by pyrolysis at different points in the system. The locations where the temperature of the pyrolysis vapors was measured are specified in Figure 2, at the end of the auger reactor (outgas 1), in the Ttype connection located at the entrance of condenser 1 (outgas 2), the intermediate area between both condensers (outgas 3), and at the exit of condenser 2 (outgas 4). The results of the pyrolysis of each biomass seem to coincide with the TG analyses of these materials. The temperature profile graph shows a decrease in the temperature at which are produced the gases in hydrochar pyrolysis. The lower content of hemicellulose and inorganic compounds present in hydrochar affects the pyrolysis reaction, since cellulose content and its availability increases to release the volatile compounds. Due to this, a change in the temperature profile is observed. Therefore, a higher thermal stability is achieved during pyrolysis.

The products of fast pyrolysis obtained from raw black spruce and from MHT optimal hydrochar are summarized in Table 5. The MHT pretreatment led to a marked effect on the distribution of pyrolysis products. The pretreated black spruce gave a lower biochar yield, with a decrease of about $13 \%$, while the liquid product yield showed an increase of about $24 \%$, and the non-condensable gas yield did not show a significant change. From the total liquid produced during fast pyrolysis, two separate products were obtained due to the nature of the condensing system used, the oily phase and an aqueous phase (Fig. 6). The distribution of the total liquid produced during pyrolysis is reported in Table 5 . Using the untreated biomass, $40.3 \%$ of the total liquid obtained corresponded to the production of the oily phase and about $46.7 \%$ corresponded to the production of the aqueous phase. After applying the pretreatment to the biomass, an advantageous effect on the distribution of the liquid products was observed. It was found that the 

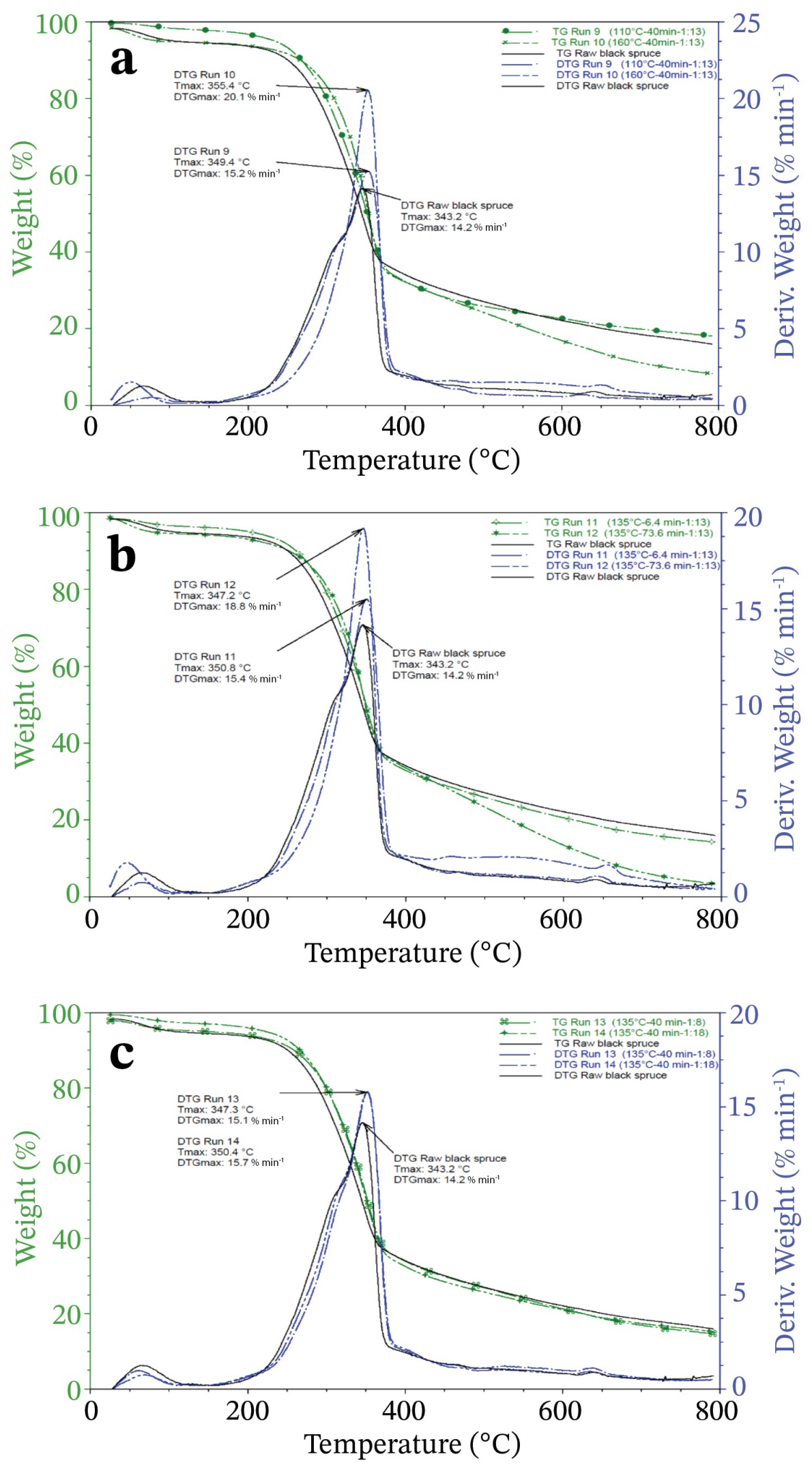

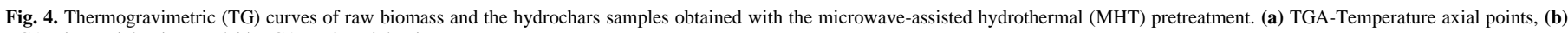
TGA-Time axial points, and (c) TGA-Ratio axial points. 
Table 4.

Thermogravimetric (TG) analysis of raw black spruce and black spruce hydrochar samples.

\begin{tabular}{|c|c|c|c|c|c|c|c|}
\hline \multicolumn{3}{|c|}{ CCD Experimental Design } & \multicolumn{5}{|c|}{ TG and DTG analysis } \\
\hline Temperature $\left({ }^{\circ} \mathrm{C}\right)$ & Time (min) & Biomass-water Ratio & $\mathbf{T}_{\mathbf{i}}{ }^{\mathbf{a}}\left({ }^{\circ} \mathbf{C}\right)$ & $\mathbf{T}_{\max }{ }^{\mathbf{b}}\left({ }^{\circ} \mathbf{C}\right)$ & $\mathbf{T}_{\mathbf{f}}{ }^{\mathbf{c}}\left({ }^{\circ} \mathbf{C}\right)$ & $D_{\text {TGax }}{ }^{d}\left(\% \min ^{-1}\right)$ & $\Delta \mathrm{T}^{\mathrm{e}}$ \\
\hline 110 & 40 & $1: 13$ & 250.9 & 349.4 & 383.0 & 15.2 & 132.1 \\
\hline 160 & 40 & $1: 13$ & 267.0 & 355.4 & 386.6 & 20.1 & 119.6 \\
\hline 135 & 6.4 & $1: 13$ & 251.6 & 350.8 & 384.5 & 15.4 & 132.9 \\
\hline 135 & 73.6 & $1: 13$ & 257.5 & 347.2 & 384.2 & 18.8 & 126.7 \\
\hline 135 & 40 & $1: 8$ & 253.4 & 347.3 & 384.9 & 15.1 & 131.5 \\
\hline 135 & 40 & $1: 18$ & 252.3 & 350.4 & 384.0 & 15.7 & 131.7 \\
\hline \multicolumn{3}{|l|}{ Raw black spruce } & 248.1 & 343.2 & 381.0 & 14.2 & 132.9 \\
\hline \multicolumn{3}{|c|}{ Optimal hydrochar $\left(160^{\circ} \mathrm{C}, 40 \mathrm{~min}, 1: 13\right)$} & 265.2 & 356.1 & 383.4 & 17.0 & 118.2 \\
\hline
\end{tabular}

${ }^{\mathrm{a}} \mathrm{T}_{\mathrm{i}}$, initial decomposition temperature. $\quad{ }^{\mathrm{c}} \mathrm{T}_{\mathrm{f}}$, final decomposition temperature.

${ }^{\mathrm{b}} \mathrm{T}_{\max }$, temperature of maximum loss rate. $\quad{ }^{\mathrm{d}} \mathrm{DTG}_{\max }$, mass loss rate of corresponding.

${ }^{\mathrm{e}} \Delta \mathrm{T}$, Temperature differential $\left(\mathrm{T}_{\mathrm{f}}-\mathrm{T}_{\mathrm{i}}\right)$.

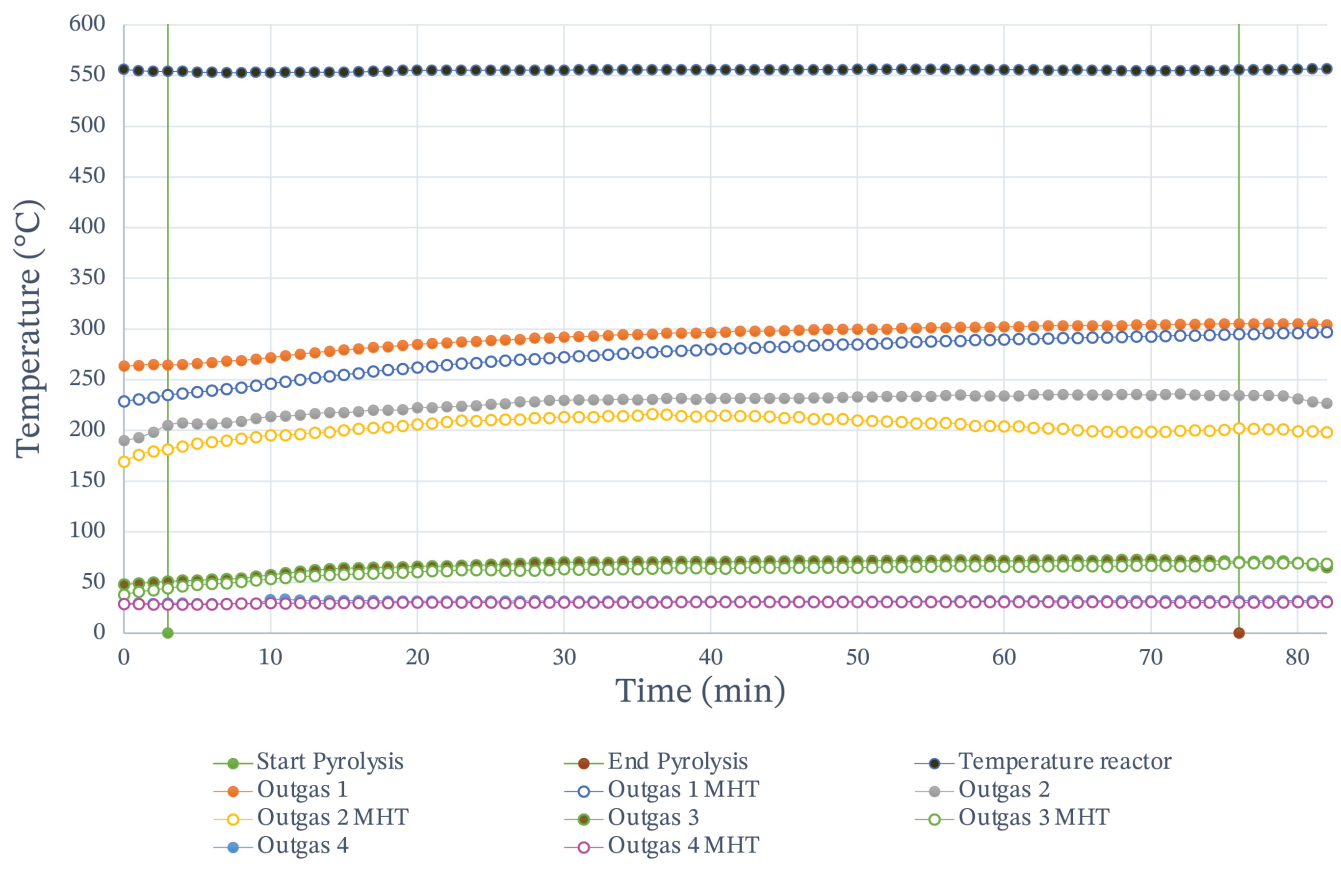

Fig. 5. Thermal profile during fast pyrolysis of raw black spruce and hydrochar.

Table 5.

Products distribution in fast pyrolysis of original and pretreated black spruce (hydrochar).

\begin{tabular}{lcc}
\hline Parameter & Raw black spruce & Black spruce hydrochar \\
\hline Biochar yield (wt\%) & 50.87 & 44.19 \\
Non-condensable gases yield (wt\%) & 33.05 & 35.87 \\
Total liquid yield (wt\%) & 16.08 & 19.93 \\
\hline Oily phase (wt\%) & 40.33 & 48.75 \\
Aqueous phase (wt\%) & 46.76 & 41.85 \\
Water content in oily phase (wt \%) & 16.31 & 10.53 \\
\hline
\end{tabular}

production of the oily phase was increased by about $8.5 \%$, while for the aqueous phase it was decreased by about $5 \%$.

Nevertheless, the MHT pretreatment not only affected the distribution of the pyrolysis products, but a substantial change in the water content of the oily part was also observed. In Table 5 , it can be seen a decrease of about $35.4 \%$ of the total water content in oily phase obtained using raw black spruce. This reduction in oil moisture is due to the partial elimination of hemicellulose and ash in black spruce. This indicates that the MHT pretreatment has a great potential in fast pyrolysis applications to improve the quality of the bio-oil.

Changes in the chemical composition of biomass after the MHT pretreatment are responsible for the variation in the distribution of pyrolysis products, due to the increased availability of cellulose content and the significant degradation of hemicellulose in biomass. Likewise, this change 

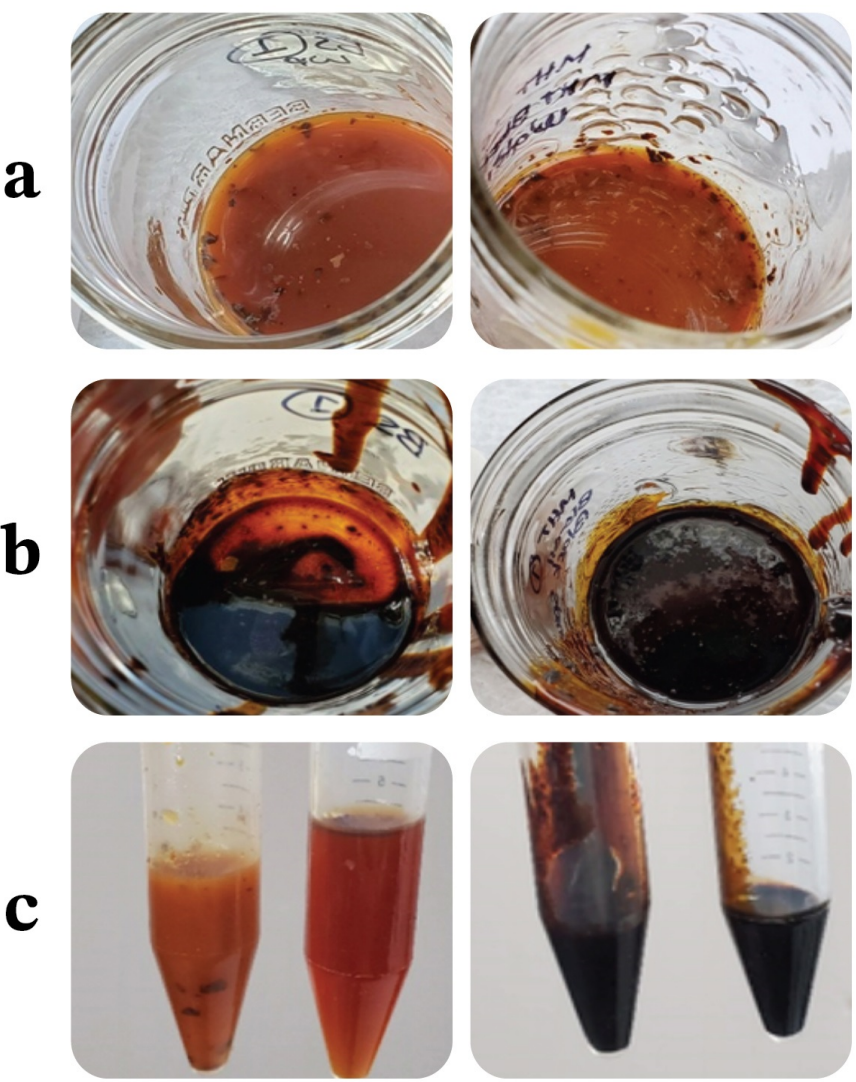

Fig. 6. Liquid products obtained from the fast pyrolysis of raw black spruce (left side) and MHTpretreated black spruce hydrochar (right side): (a) aqueous phase, (b) oily phase, and (c) comparison of the aqueous and oily phase.

in chemical composition of the material used in pyrolysis, is responsible for the change in appearance of the liquid products, specifically in the coloring of aqueous part, which can be seen in Figure 6 . Hence, bio-oil yield obtained through fast pyrolysis of MHT-pretreated black spruce hydrochar is enhanced. In addition, reducing the content of inorganic compounds present in the ash of pretreated biomass can also contribute to slowing down the formation of gaseous and biochar products, as well as to improving the bio-oil yield in fast pyrolysis by reducing the catalytic cracking reaction. Similar results were obtained by applying hydrothermal treatment in conventional equipment (Chang et al., 2013).

\subsection{GC-MS analysis of bio-oil}

The oily phase obtained from fast pyrolysis of raw black spruce and MHT optimal hydrochar are named B-BS and B-MHT, respectively. The chemical composition of the bio-oils was qualitatively examined by GC-MS. Figure 7 shows the relative content of the main organic compounds identified in the biooils obtained from both, black spruce and hydrochar. The identified compounds are grouped into nine general categories, namely carboxylic acids, nonaromatic aldehydes, non-aromatic ketones, alcohols, carbohydrates, benzenediols, furans, phenols, and methoxyphenol derivatives.

Detailed information of chemical composition of both bio-oils is shown in Table 6. The main compound of the bio-oil obtained from raw black spruce are guaiacols (methoxyphenols), followed by non-aromatic ketones and carbohydrates, in which levoglucosan is the only compound detected. Owing to the MHT pretreatment of the black spruce, a significant change in the chemical composition of the bio-oil was observed. The bio-oil obtained from MHT hydrochar contained a lower content of acids, phenols, methoxyphenols, alcohols, ketones, and aldehydes. This is mainly due to the reduction of hemicellulose in black spruce, which also increases its thermal stability (Chang et al., 2013).
The main organic acid present in bio-oils is acetic acid and, after MHT pretreatment, its relative content decreased from $7.23 \%$ to $4.98 \%$. This was due to the removal of acetyl group present in hemicellulose structure of the biomass. Moreover, the reduced ash content in the resulting hydrochar played an important role in reducing the acid content and low molecular weight compounds in the bio-oil, since the inorganic salts present in the ash act as catalysts in the primary reactions of pyrolysis (Alvarez-Chavez et al. 2019b). The relative content of phenols and methoxyphenols was reduced, although not significantly. Likewise, it was observed that the relative content of ketones, aldehydes, and alcohols was slightly reduced (ketones from $17.7 \%$ to $14.6 \%$, aldehydes from $7.2 \%$ to $6.2 \%$, and alcohols from $3.3 \%$ to $1.6 \%$ ). The groups of chemicals that remained constant in their relative content were furans and benzediols. However, although in general the furan group remained almost constant, it is necessary to note that compounds such as furfural, 2-furanmethanol, 2(5H)-Furanone decreased while 2(3H)-Furanone, dihydro-4-hydroxy- and 2-Furancarboxaldehyde, 5(hydroxymethyl)- increased. The reason for this is that the first group of furans is produced mainly from hemicellulose and the second group is produced mainly from cellulose, which increased during MHT pretreatment (Chang et al., 2013).

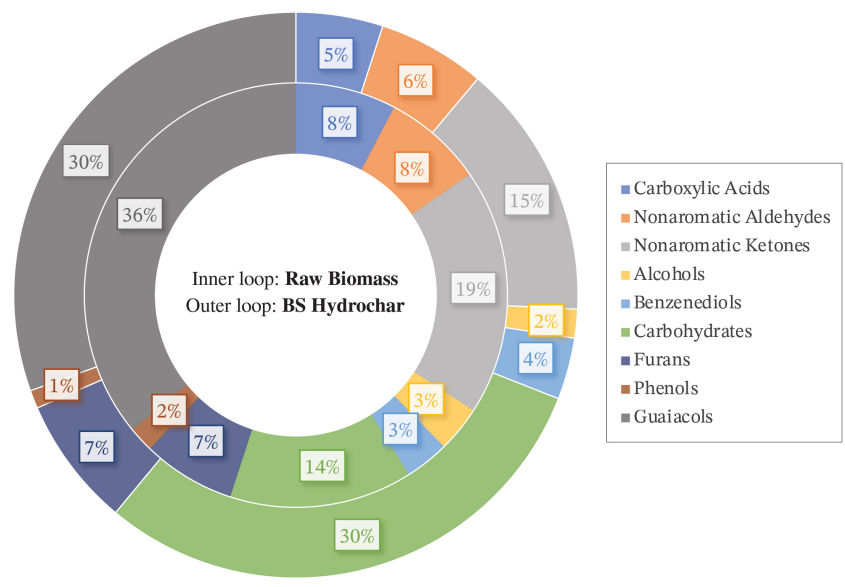

Fig. 7. Relative content of chemical groups identified in the bio-oil obtained from raw black spruce (B-BS) and hydrochar (B-MHT).

However, the most significant change was the content of carbohydrates, namely levoglucosan, which increased more than twice from $13.2 \%$ to $30.0 \%$ relative content. This remarkable increase of sugars in the bio-oil is due to the MHT pretreatment which increased the accessibility and quantity of cellulose, as well as the removal of inorganic compounds in the biomass, reducing the opening of the sugar rings during pyrolysis (Dai et al., 2018). An interesting study was conducted to evaluate the effect of inorganic salts on cellulose under the pyrolysis reaction (Patwardhan et al., 2010). Their results showed that the reaction products of primary pyrolysis are formed by competitive reactions. Minimal inorganic salt concentrations are enough to dramatically change the chemical composition of the products. This is due to the inorganic compounds catalyzing the primary reactions, that leads to the formation of lower molecular weight species, such as formic acid, glycolaldehyde, and acetol, from the cellulose. And finally, as a result of faster reactions, lower yields of levoglucosan were observed. These results have been confirmed by other authors (Pecha et al., 2015; Chang et al. 2018).

In comparison with other studies of conventional hydrothermal treatment, the same trend in decrease of acetones, aldehydes, acids, and phenols was observed, while the trend in increase of sugar or carbohydrate content was confirmed (Le Roux et al., 2015; Zheng et al., 2015; Yao and $\mathrm{Ma}, 2018)$. The same trend is generally observed when contrasting the current results with previous works, evaluating the effect of MHT 
Table 6.

Chemical composition of B-BS and B-MHT (\% of relative content).

\begin{tabular}{|c|c|c|c|c|c|}
\hline \multirow{2}{*}{ No. } & \multirow{2}{*}{ Retention time } & \multirow{2}{*}{ Compounds } & \multirow{2}{*}{ Chemical group } & \multicolumn{2}{|c|}{ Relative content (\%) } \\
\hline & & & & B-BS & B-MHT \\
\hline \multirow[t]{2}{*}{1} & 3.687 & Acetic acid, methyl ester & Carboxylic Acids & 7.23 & 4.98 \\
\hline & & Total Carboxylic Acids & & 7.23 & 4.98 \\
\hline 2 & 3.898 & 1,4-Butanedial & Nonaromatic Aldehydes & 4.62 & 1.58 \\
\hline 3 & 11.238 & Acetaldehyde, hydroxy- (Glycolaldehyde) & NA Aldehydes & 0.80 & -- \\
\hline 4 & 15.22 & Butanal, 3-methyl & NA Aldehydes & 0.98 & 1.26 \\
\hline \multirow[t]{2}{*}{5} & 15.79 & Heptanal & NA Aldehydes & 0.80 & 3.32 \\
\hline & & Total Nonaromatic Aldehydes & & 7.2 & 6.2 \\
\hline 6 & 3.626 & 1-Hydroxy-2-butanone & Nonaromatic Ketones & 1.10 & -- \\
\hline 7 & 4.154 & 2-propanone, 1-hydroxy & Nonaromatic Ketones & 1.85 & 1.33 \\
\hline 8 & 5.826 & 2-Butanone & Nonaromatic Ketones & 6.62 & 6.16 \\
\hline 9 & 6.24 & 2-Propanone, 1-(acetyloxy)- & Nonaromatic Ketones & 0.97 & 0.00 \\
\hline 10 & 7.706 & 1,2-Cyclopentanedione & Nonaromatic Ketones & 2.59 & 2.28 \\
\hline 11 & 10.033 & 3,4-Dihydroxy-3-cyclobutene-1,2-dione & Nonaromatic Ketones & 2.03 & 2.86 \\
\hline \multirow[t]{2}{*}{12} & 10.918 & 2-Cyclopenten-1-one, 2-hydroxy-3-methyl- & Nonaromatic Ketones & 2.51 & 1.99 \\
\hline & & Total Nonaromatic Ketones & & 17.7 & 14.6 \\
\hline 13 & 4.252 & Glycidol & Alcohols & 2.58 & 1.65 \\
\hline \multirow[t]{2}{*}{14} & 6.185 & Cyclobutanol & Alcohols & 0.72 & -- \\
\hline & & Total Alcohols & & 3.3 & 1.6 \\
\hline 15 & 16.137 & 1,2-Benzenediol & Benzenediols & 2.38 & 2.32 \\
\hline \multirow[t]{2}{*}{16} & 18.688 & 1,2-Benzenediol, 3-methyl- & Benzenediols & 0.78 & 1.20 \\
\hline & & Total Benzenediols & & 3.2 & 3.5 \\
\hline \multirow[t]{2}{*}{17} & 22.487 & 1,6-Anhydro-. beta. -D-glucopyranose (levoglucosan) & Carbohydrates & 13.2 & 30.0 \\
\hline & & Total Carbohydrates & & 13.2 & 30.0 \\
\hline 18 & 5.142 & Furfural & Furans & 1.61 & 1.39 \\
\hline 19 & 5.747 & 2-Furanmethanol & Furans & 0.88 & 0.48 \\
\hline 20 & 7.425 & 2(5H)-Furanone & Furans & 2.70 & 1.59 \\
\hline 21 & 16.374 & 2(3H)-Furanone, dihydro-4-hydroxy- & Furans & 0.64 & 2.45 \\
\hline \multirow[t]{2}{*}{22} & 16.974 & 2-Furancarboxaldehyde, 5-(hydroxymethyl)- & Furans & 0.84 & 1.51 \\
\hline & & Total Furans & & 6.7 & 7.4 \\
\hline 23 & 9.573 & Phenol & Phenols & 0.72 & -- \\
\hline \multirow[t]{2}{*}{24} & 12.478 & Phenol, 4-methyl- & Phenols & 1.11 & 1.05 \\
\hline & & Total Phenols & & 1.8 & 1.0 \\
\hline 25 & 12.912 & Phenol, 2-methoxy- & Guaiacols & 5.11 & 3.30 \\
\hline 26 & 16.015 & Phenol, 2-methoxy-4-methyl- & Guaiacols & 5.60 & 6.06 \\
\hline 27 & 18.46 & Phenol, 4-ethyl-2-methoxy- & Guaiacols & 1.69 & 1.67 \\
\hline 28 & 19.411 & 2-methoxy-4-vinylphenol (4-vinylguaiacol) & Guaiacols & 3.51 & 3.73 \\
\hline 29 & 20.581 & Eugenol & Guaiacols & 3.00 & 2.61 \\
\hline 30 & 21.628 & Vanillin & Guaiacols & 2.04 & 2.22 \\
\hline 31 & 21.9 & Phenol, 2-methoxy-4-(1-propenyl)- & Guaiacols & 1.18 & 1.12 \\
\hline 32 & 22.943 & Phenol, 2-methoxy-4-(1-propenyl)-, (E)- (trans-Isoeugenol) & Guaiacols & 6.82 & 7.01 \\
\hline 33 & 23.833 & Ethanone, 1-(4-hydroxy-3-methoxyphenyl)- (Acetoguaiacon) & Guaiacols & 1.55 & -- \\
\hline 34 & 24.932 & Homovanillyl alcohol & Guaiacols & 0.74 & 0.88 \\
\hline 35 & 27.614 & Benzeneacetic acid, 4-hydroxy-3-methoxy- (Homovanillic acid) & Guaiacols & 0.72 & -- \\
\hline \multirow[t]{2}{*}{36} & 29.468 & 4-Hydroxy-2-methoxycinnamaldehyde & Guaiacols & 1.83 & 1.84 \\
\hline & & Total Guaiacols (methoxy phenols) & & 33.8 & 30.4 \\
\hline
\end{tabular}


pretreatment on vapors composition produced during pyrolysis (Py-GC-MS). Dai et al. (2017) in a study reported that MHT at conditions of $150{ }^{\circ} \mathrm{C}$ for 30 min led to an increase in relative content of $60 \%$ in levoglucosan and about $23 \%$ in phenolic compounds, while they observed a reduction of $11 \%$ in acetic acid. In the same study, the authors tested increasing the temperature to $190{ }^{\circ} \mathrm{C}$ for 30 min, obtaining an increase of $70 \%$ in levoglucosan and $28 \%$ in phenolic compounds while acetic acid presented a reduction of $31 \%$. However, in this study, using the same pretreatment concept and an auger pyrolizer, it was observed that the optimal MHT conditions of $160{ }^{\circ} \mathrm{C}$ for $40 \mathrm{~min}$ resulted in a $128 \%$ increase in levoglucosan, and a $31 \%$ reduction in acetic acid. Nevertheless, the content of phenolic compounds decreased by about $11 \%$, due to the change in chemical composition and lignin content of hydrochar.

The results of the present study reveal that MHT pretreatment significantly promotes the formation of levoglucosan, as well as the reduction of acids and other light oxygenated organic compounds. Therefore, MHT pretreatment might offer the possibility of using bio-oil as a source for the extraction of chemicals of interest, such as levoglucosan, besides the use of bio-oil as fuel in stationary combustion applications. Levoglucosan has a commercial price, according to Sigma-Aldrich, of USD $110 \mathrm{~g}^{-1}$ and it is commonly used for the synthesis of high-value compounds and materials (esters, films, binders, UV polymers, and singular drugs) (Ermolenko, 2013). Recent studies have demonstrated the feasibility of extraction and subsequent distillation of levoglucosan from pyrolytic oil (Wang et al., 2016; Dobele et al., 2020). Hence, it is recommended to deepen in this subject, for optimization of levoglucosan production using pyrolysis plant at pilot level.

\section{Conclusions and future directions}

The effect of temperature, time, and biomass-water ratio in the MHT pretreatment was evaluated and then it was optimized through response surface methodology as an upgrading technique to the biomass before fast pyrolysis. Hydrochar characteristics indicates that MHT can reduce the ash content and hemicellulose which was both promoted by the augment of temperature. The optimal hydrochar produced showed a higher thermal stability due to the dissociation of acetyl groups, present in hemicellulose. Consequently, the use of optimal hydrochar in fast pyrolysis resulted in a bio-oil with an enhanced quality, with a $35 \%$ decrease in moisture content, lower relative content of acids, and a levoglucosan production dramatically promoted. Therefore, MHT pretreatment is an attractive and efficient technique for improving the quality of pyrolytic bio-oil. For future work, it is sought to combine the MHT treatment with fractionation techniques of different phases of the bio-oil, to obtain a phase enriched in levoglucosan to seek its extraction.

\section{Acknowledgments}

We gratefully acknowledge the financial support from Mexico's Secretariat of Energy, the National Council on Science and Technology (CONACYTSENER), Bioresource Engineering Department of McGill University, and the Research and Development Institute for the Agri-Environment (IRDA). The authors would also like to thank Yvan Gariepy (McGill University), and Joahnn Palacios (IRDA) for their technical assistance.

\section{References}

[1] Alvarez-Chavez, B.J., Godbout, S., Le Roux, E., Palacios, J.H., Raghavan, V., 2019a. Bio-oil yield and quality enhancement through fast pyrolysis and fractional condensation concepts. Biofuel Res. J. 24, 10541064

[2] Alvarez-Chavez, B.J., Godbout, S., Palacios-Rios, J.H., Le Roux, E., Raghavan, V., 2019b. Physical, chemical, thermal and biological pretreatment technologies in fast pyrolysis to maximize bio-oil quality: a critical review. Biomass Bioenergy. 128, 105333.

[3] Asadieraghi, M., Daud, W.M.A.W., 2014. Characterization of lignocellulosic biomass thermal degradation and physiochemical structure: effects of demineralization by diverse acid solutions. Energy Convers. Manage. 82, 71-82.

[4] Beneroso, D., Monti, T., Kostas, E.T., Robinson, J., 2017. Microwave pyrolysis of biomass for bio-oil production: scalable processing concepts. Chem. Eng. J. 316, 481-498.
[5] Bhattacharya, M., Basak, T., 2016. A review on the susceptor assisted microwave processing of materials. Energy. 97, 306-338

[6] Brassard, P., Godbout, S., Pelletier, F., Raghavan, V., Palacios, J.H. 2018. Pyrolysis of switchgrass in an auger reactor for biochar production: a greenhouse gas and energy impacts assessment. Biomass Bioenergy. 116, 99-105.

[7] Brunner, M., Li, H., Zhang, Z., Zhang, D., Atkin, R., 2019. Pinewood pyrolysis occurs at lower temperatures following treatment with choline-amino acid ionic liquids. Fuel. 236, 306-312.

[8] Campuzano, F., Brown, R.C., Martinez, J.D., 2019. Auger reactors for pyrolysis of biomass and wastes. Renew. Sust. Energy Rev. 102, 372-409.

[9] Chang, Q., Gao, R., Li, H., Yu, G., Liu, X., Wang, F., 2018. Understanding of formation mechanisms of fine particles formed during rapid pyrolysis of biomass. Fuel. 216, 538-547.

[10] Chang, S., Zhao, Z., Zheng, A., Li, X., Wang, X., Huang, Z., He, F., Li, H., 2013. Effect of hydrothermal pretreatment on properties of bio-oil produced from fast pyrolysis of eucalyptus wood in a fluidized bed reactor. Bioresour. Technol. 138, 321-328.

[11] Dai, L., He, C., Wang, Y., Liu, Y., Yu, Z., Zhou, Y., Fan, L., Duan, D., Ruan, R., 2017. Comparative study on microwave anc conventional hydrothermal pretreatment of bamboo sawdust: hydrochar properties and its pyrolysis behaviors. Energy Convers. Manage. 146, 1-7.

[12] Dai, L., He, C., Wang, Y., Liu, Y., Ruan, R., Yu, Z., Zhou, Y., Duan, D., Fan, L., Zhao, Y., 2018. Hydrothermal pretreatment of bamboo sawdust using microwave irradiation. Bioresour. Technol. 247, 234241.

[13] Dobele, G., Zhurinsh, A., Volperts, A., Jurkjane, V., Pomilovskis, R. Meile, K., 2020. Study of levoglucosenone obtained in analytical pyrolysis and screw-type reactor, separation and distillation. Wood Sci. Technol. 54(2), 383-400.

[14] Ermolenko, M.S., 2013. Convenient and efficient synthesis of 2, 4 dideoxy-levoglucosan. Synth. Commun. 43(21), 2841-2845.

[15] Ferreira, S.C., Bruns, R.E., Ferreira, H.S., Matos, G.D., David, J.M., Brandao, G.C., da Silva, E.P., Portugal, L.A., Reis, P.S., Souza, A.S. dos Santos, W.N.L., 2007. Box-Behnken design: an alternative for the optimization of analytical methods. Anal. Chim. Acta. 597(2), 179186.

[16] Hilbers, T.J., Wang, Z., Pecha, B., Westerhof, R.J., Kersten, S.R., Pelaez-Samaniego, M.R., Garcia-Perez, M., 2015. Cellulose-Lignin interactions during slow and fast pyrolysis. J. Anal. Appl. Pyrolysis 114, 197-207.

[17] Holopainen-Mantila, U., Marjamaa, K., Merali, Z., Kasper, A., de Bot, P., Jaaskelainen, A.S., Waldron, K., Kruus, K., Tamminen, T. 2013. Impact of hydrothermal pre-treatment to chemical composition, enzymatic digestibility and spatial distribution of cell wall polymers. Bioresour. Technol. 138, 156-162.

[18] Imran, A., Bramer, E.A., Seshan, K., Brem, G., 2018. An overview of catalysts in biomass pyrolysis for production of biofuels. Biofuel Res. J. 5(4), 872-885

[19] Jalalifar, S., Abbassi, R., Garaniya, V., Salehi, F., Papari, S. Hawboldt, K., Strezov, V., 2020. CFD analysis of fast pyrolysis process in a pilot-scale auger reactor. Fuel. 273, 117782.

[20] Kalargaris, I., Tian, G., Gu, S., 2017. Influence of advanced injection timing and fuel additive on combustion, performance, and emission characteristics of a DI diesel engine running on plastic pyrolysis oil. J. Combust., 2017

[21] Kambo, H.S., Dutta, A., 2015. A comparative review of biochar and hydrochar in terms of production, physico-chemical properties and applications. Renew. Sust. Energy Rev. 45, 359-378.

[22] Krutof, A., Hawboldt, K., 2016. Blends of pyrolysis oil, petroleum, and other bio-based fuels: a review. Renew. Sust. Energy Rev. 59, 406-419

[23] Krutof, A., Hawboldt, K.A., 2020. Thermodynamic model of fast pyrolysis bio-oil advanced distillation curves. Fuel. 261, 116446

[24] Lam, S.S., Mahari, W.A.W., Ma, N.L., Azwar, E., Kwon, E.E., Peng, W., Chong, C.T., Liu, Z., Park, Y.K., 2019a. Microwave pyrolysis valorization of used baby diaper. Chemosphere. 230, 294-302. 
[25] Lam, S.S., Mahari, W.A.W., Ok, Y.S., Peng, W., Chong, C.T., Ma, N.L., Chase, H.A., Liew, Z., Yusup, S., Kwon, E.E., Tsang, D.C., 2019 b. Microwave vacuum pyrolysis of waste plastic and used cooking oil for simultaneous waste reduction and sustainable energy conversion: recovery of cleaner liquid fuel and techno-economic analysis. Renew. Sust. Energy Rev. 115, 109359.

[26] Le Roux, E., Chaouch, M., Diouf, P.N., Stevanovic, T., 2015. Impact of a pressurized hot water treatment on the quality of bio-oil produced from aspen. Biomass Bioenergy. 81, 202-209.

[27] Patwardhan, P.R., Satrio, J.A., Brown, R.C., Shanks, B.H., 2010. Influence of inorganic salts on the primary pyrolysis products of cellulose. Bioresour. Technol. 101(12), 4646-4655.

[28] Pecha, B., Arauzo, P., Garcia-Perez, M., 2015. Impact of combined acid washing and acid impregnation on the pyrolysis of Douglas fir wood. J. Anal. Appl. Pyrolysis. 114, 127-137.

[29] Pourkarimi, S., Hallajisani, A., Alizadehdakhel, A., Nouralishahi, A., 2019. Biofuel production through micro- and macroalgae pyrolysis-a review of pyrolysis methods and process parameters. J. Anal. Appl. Pyrolysis. 142, 104599.

[30] Qureshi, S.S., Nizamuddin, S., Baloch, H.A., Siddiqui, M.T.H., Mubarak, N.M., Griffin, G.J., 2019. An overview of OPS from oil palm industry as feedstock for bio-oil production. Biomass Convers. Biorefin. 9(4), 827841

[31] Ren, X., Gou, J., Wang, W., Li, Q., Chang, J., Li, B., 2013. Optimization of bark fast pyrolysis for the production of phenol-rich bio-oil. Bioresources. 8(4), 6481-6492.

[32] Sharma, H.B., Sarmah, A.K., Dubey, B., 2020. Hydrothermal carbonization of renewable waste biomass for solid biofuel production: a discussion on process mechanism, the influence of process parameters, environmental performance and fuel properties of hydrochar. Renew. Sust. Energ. Rev. 123, 109761

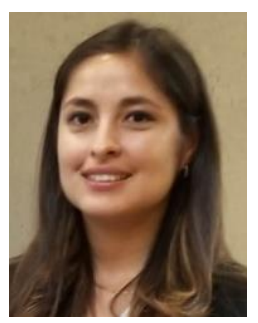

Brenda J Alvarez Chavez completed her bachelor's degree in Chemical Engineering at the University of Veracruz (Mexico) where she also completed her master's degree in Energy Engineering in 2014. Brenda Alvarez has professional experience in the development and implementation of different renewable energy projects within the public and private sectors in Mexico, covering photovoltaic, photothermal and bioenergy applications. Brenda Alvarez is currently a $\mathrm{PhD}$ candidate in Bioresource Engineering at McGill University (Canada). During her doctorate, she has studied different techniques to improve the quality of biofuels obtained by fast pyrolysis, using statistical optimization methods. Her research interests include thermochemical processes and renewable energies, particularly bioenergy from agroforestry residues.
[33] Shen, D.K., Siderius, D.W., Krekelberg, W.P., Hatch, H.W., 2017 NIST standard reference simulation website, September 2017 ed National institute of standards and technology, gaithersburg MD, 20899.

[34] Soltanian, S., Lee, C.L., Lam, S.S., 2020. A review on the role of hierarchical zeolites in the production of transportation fuels through catalytic fast pyrolysis of biomass. Biofuel Res. J. 7(3), 1217-1234.

[35] Wang, J., Wei, Q., Zheng, J., Zhu, M., 2016. Effect of pyrolysis conditions on levoglucosan yield from cotton straw and optimization of levoglucosan extraction from bio-oil. J. Anal. Appl. Pyrolysis. 122, 294-303

[36] Wu, X., Wu, Y., Wu, K., Chen, Y., Hu, H., Yang, M., 2015. Study on pyrolytic kinetics and behavior: the co-pyrolysis of microalgae and polypropylene. Bioresour. Technol. 192, 522-528.

[37] Yao, Z., Ma, X., 2018. Effects of hydrothermal treatment on the pyrolysis behavior of Chinese fan palm. Bioresour. Technol. 247 504-512.

[38] Yu, J., Paterson, N., Blamey, J., Millan, M., 2017. Cellulose, xylan and lignin interactions during pyrolysis of lignocellulosic biomass. Fuel. 191, 140-149.

[39] Zhang, S., Dong, Q., Zhang, L., Xiong, Y., 2016. Effects of water washing and torrefaction on the pyrolysis behavior and kinetics of rice husk through TGA and Py-GC/MS. Bioresour. Technol. 199, 352361.

[40] Zheng, A., Zhao, Z., Chang, S., Huang, Z., Zhao, K., Wei, G., He, F., Li, H., 2015. Comparison of the effect of wet and dry torrefaction on chemical structure and pyrolysis behavior of corncobs. Bioresour. Technol. 176, 15-22.

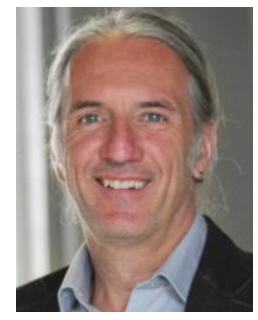

Stéphane Godbout (P.Eng., agr., Ph.D.) earned a bachelor's degree in agricultural engineering from Université Laval, where he also completed a master's degree in agricultural engineering in 1990, and a doctoral degree in civil engineering in 1996 While a graduate student he did research that helped to change the design standards for circular slurry storage tanks made of reinforced concrete. Stéphane Godbout spent three years at Centre de développement du porc du Québec and then joined IRDA in November 2000. His research focuses on livestock breeding and manure management strategies, and on the impact of gas and odour emissions on co-existence. In the past few years, he has helped set up mobile laboratories to measure airborne emissions from livestock buildings. More recently, Stéphane initiated a research program targeting the conversion of residual biomasses (energy, materials, bedding, etc.) and established a specialized infrastructure (LEAD: a laboratory for developing green energy applications in agriculture) to pursue these objectives. While engaged in a refresher course at the Silsoe Research Institute in Great Britain from 2002 to 2003, he developed a new passive sampler for measuring GHG emissions. In 2003 he received both a "Young Engineer of the Year" Award from Association québécoise des ingénieurs en agroalimentaire, a "Young Engineer of the Year" and John-Turnbull Award from the Canadian Society for Bioengineering (CSBE/SCGAB). 


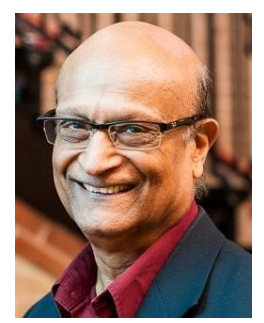

Vijaya Raghavan, Treasurer, RSC, is a James McGill Professor in the Department of Bioresource Engineering (FAES) at McGill University. He is Graduate Program Director for Bioresource Engineering, He was inducted into the Royal Society of Canada (RSC) in 2012, and into the Engineering Institute of Canada in 2017. He was President of the Canadian Society for Bioengineering from 2016 to 2017 and was President of the Academy of Science of the RSC from 2017 to 2019. Prof. Raghavan has made key contributions to the development of knowledge and technologies in the area of post-production technologies related to drying, storage, thermal and nonthermal treatments of food, valorization of agricultural and food by-products leading to more than 630 articles, 53 book chapters, and 7 patents. He has developed particulate medium-based heating and drying systems for heat treatment of grains and biological materials. He is studying the use of electrotechnologies such as microwaves (MW), radiofrequency (RF), and pulsed electric fields (PEF) not only for the drying and thermal treatment of crops, but also for MW-assisted extraction of bioactive compounds from plant materials. He has directed four CIDA and one IDRC-CIFSRF funded projects in India and China, in which he has implemented his expertise in post-production technologies to assure food security and safety. These projects improved the capacity of local universities and NGOs for research and development in agricultural engineering, while sharing knowledge and appropriate technologies with farming communities to reduce post-harvest losses. Training on methods for food processing and assuring food safety has fostered the startup of small enterprises by women self-help groups and entrepreneurs from farming communities. These activities have resulted in economic benefits to these communities and especially to the women. He has been a co-investigator or as a consultant in other CIDA and IDRC funded projects in Africa and India. Awards/Honours: Faculty of Agricultural and Environmental Sciences Award for Teaching Excellence, 1992,1996; Maple Leaf Award of the CSAE, 1997; Outstanding Indo-Canadian Award from the National Indo-Canadian Council, 2002; Natural Sciences \& Engineering Research Council of Canada (NSERC) Certificate of Achievements, 2004; Proctor and Gamble Company Award for Excellence in Drying Research, 2006; Doctor of Science (Honoris Causa), TNAU 2007, and UAS-Dharwad 2010; David Thomson Award for Excellence in Graduate Supervision \& Teaching, 2007; Lifetime Achievement Award by the Drying Technology Journal, 2008; Kishida International Award, ASABE, 2017. ASABE International Food Engineering Award, 2018. Other Fellowships: Foreign Fellow of Natioanl Academy of Agricultural Sciencess, India, Indian Society of Agricultural Engineers (ISAE); Indian Institution of Engineers (IIE); American Society of Mechanical Engineers (ASME), ASABE, the American Society of Agricultural and Biological Engineers); CSBE, the Canadian Society for Bioengineering. 